\title{
\begin{tabular}{l|l} 
Mitraries & DSpace@MIT
\end{tabular}
}

\author{
MIT Open Access Articles
}

\section{A Continuous Homologation of Esters: An Efficient Telescoped Reduction-Olefination Sequence}

The MIT Faculty has made this article openly available. Please share how this access benefits you. Your story matters.

Citation: Webb, Damien, and Timothy F. Jamison. “A Continuous Homologation of Esters: An Efficient Telescoped Reduction-Olefination Sequence." Organic Letters 14.10 (2012): 2465-2467.

As Published: http://dx.doi.org/10.1021/ol300722e

Publisher: American Chemical Society (ACS)

Persistent URL: http://hdl.handle.net/1721.1/76285

Version: Author's final manuscript: final author's manuscript post peer review, without publisher's formatting or copy editing

Terms of Use: Article is made available in accordance with the publisher's policy and may be subject to US copyright law. Please refer to the publisher's site for terms of use. 


\title{
A Continuous Homologation of Esters: An Efficient Telescoped Reduction-Olefination Sequence
}

\author{
Damien Webb and Timothy F. Jamison* \\ Department of Chemistry, Massachusetts Institute of Technology, Cambridge, \\ Massachusetts 02139 \\ tfj@mit.edu
}

Received Date (will be automatically inserted after manuscript is accepted)

\section{ABSTRACT}

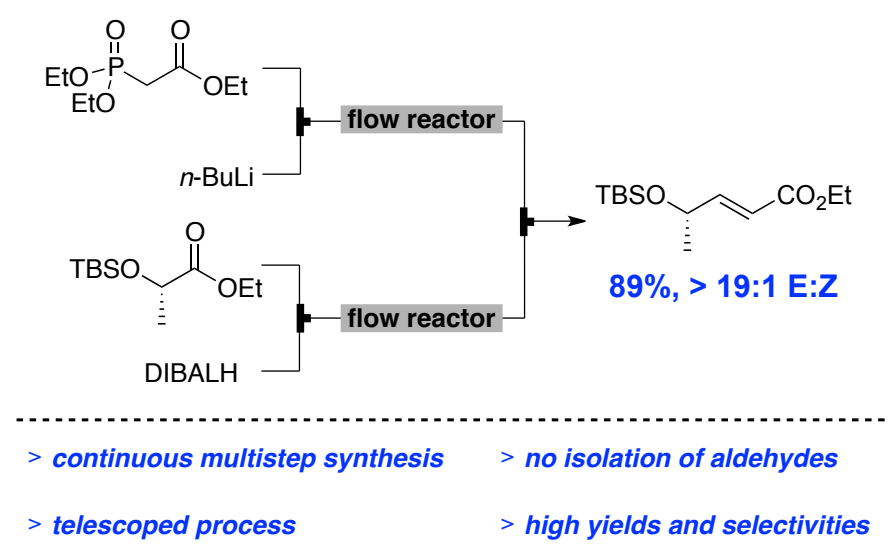

A continuous protocol for the 2-carbon homologation of esters to $\alpha, \beta$-unsaturated esters is described. This multireactor homologation telescopes an ester reduction, phosphonate deprotonation and Horner-Wadsworth-Emmons olefination, thus converting a three-operation procedure into a single, uninterrupted system that eliminates the need for isolation or purification of the aldehyde intermediates. The homologated products are obtained in high yield and selectivity.

The 2-carbon homologation of esters to $\alpha, \beta$ unsaturated esters is a ubiquitous sequence in synthetic organic chemistry. This fundamental assembly exercise can be achieved in 2 synthetic steps that comprise the Horner-Wadsworth-Emmons olefination ${ }^{1}$ of an aldehyde that is prepared by the partial reduction of an ester using diisobutylaluminum hydride ${ }^{2}$ (DIBALH) (Figure 1(a)). However, the capriciousness often observed for the DIBALH reduction step has conferred such a notorious reputation upon this transformation that this sequence is

${ }^{1}$ Maryanoff, B. E.; Reitz, A. B. Chem. Rev. 1989, 89, 863-927.

${ }^{2}$ Zakharkin, L. I.; Khorlina, I. M. Tetrahedron Lett. 1962, 619-620. rarely used. ${ }^{3}$ Accordingly, one often resorts to a multistep alternative: Reduction of the ester to a primary alcohol and then oxidation to the aldehyde, followed by the olefination step (Figure 1(b)). This 3-step approach is undesirable as it generates additional waste, in addition to requiring the isolation-and often purification-of aldehydes that may be troublesome to handle.

${ }^{3}$ Burns, N. Z.; Baran, P. S.; Hoffmann, R. W. Angew. Chem. Int. Ed. 2009, 48, 2854-2867. 
(a) 2-step sequence (desirable but DIBALH reduction is capricious)

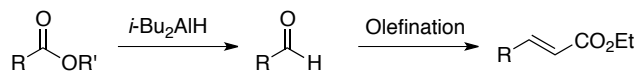

(b) 3-step sequence (common but undesirable)

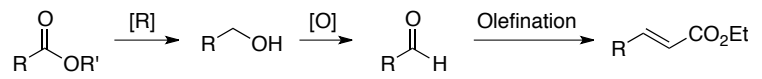

(c) This Work: A Continuous and Telescoped 'Homologator'

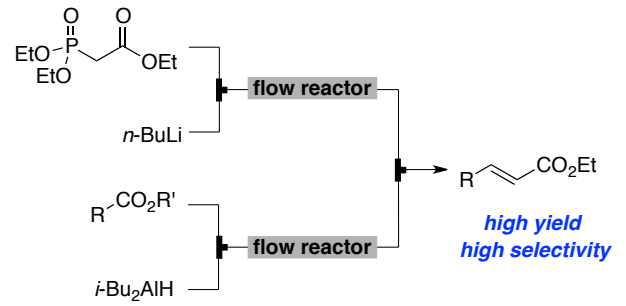

Figure 1. Strategies for the 2-carbon homologation of esters to $\alpha, \beta$-unsaturated esters.

Although one-pot procedures for this homologation sequence have been reported, ${ }^{4}$ this approach has not been widely used. Moreover, the requirement for cryogenic temperatures renders this method undesirable for use on a large scale. Recently, continuous flow methods ${ }^{5,6}$ have emerged as an enabling tool, particularly for the execution of highly exothermic and fast chemical reactions involving organometallic reagents. ${ }^{7}$ In this regard, we reported a simple flow system for the continuous DIBALH reduction of esters that facilitated the rapid optimization of multiple reaction parameters and was successfully applied to yield a selective and reproducible synthesis of aldehydes from esters. ${ }^{8}$ In this Letter we disclose the development of a continuous

4 For one-pot DIBALH reduction/olefination sequences see: (a) Takacs, J. M.; Helle, M. A.; Seely, F. L. Tetrahedron Lett. 1986, 27, 1257-1260. (b) Hoye, T. R.; Kopel, L. C.; Ryba, T. D. Synthesis 2006, $1572-1574$.

${ }^{5}$ For recent general reviews on continuous flow chemistry see: (a) Wirth, T. Microreactors in organic synthesis and catalysis Wiley-VCH: Weinheim, 2008. (b) Hartman, R. L.; Jensen, K. F. Lab Chip 2009, 9 2495. (c) Mason, B. P.; Price, K. E.; Steinbacher, J. L.; Bogdan A. R.; McQuade, D. T. Chem. Rev. 2007, 107, 2300. (d) Geyer, K.; Gustafsson T.; Seeberger, P. H. Synlett 2009, 2382. (e) Kirschning, A.; Solodenko W.; Mennecke, K. Chem. Eur. J. 2006, 12, 5972. (f) Wiles C.; Watts, P. Eur. J. Org. Chem. 2008, 10, 1655. (g) Ley S. V.; Baxendale I. R. Proceedings of Bosen Symposium, Systems Chemistry 2008, 65. (h) Jähnisch, K.; Hessel, V.; Löwe, H.; Baerns, M. Angew. Chem., Int. Ed. $\mathbf{2 0 0 4}, 43,406$.

${ }^{6}$ For recent reports from our laboratory see: (a) Bedore, M. W.; Zaborenko, N.; Jensen, K. F.; Jamison, T. F. Org. Process Res. Dev. 2010, 14, 432-440. (b) Sniady, A.; Bedore, M. W.; Jamison, T. F. Angew. Chem. Int. Ed. 2011, 50, 2155-2158. (c) Palde, P. B.; Jamison, T. F. Angew. Chem. Int. Ed. 2011, 50, 3525-3528. (d) Zhang, Y.; Jamison, T. F.; Patel, S. J.; Mainofli, N. Org. Lett. 2010, 13, 280-283. (e) Gutierrez, A. C.; Jamison, T. F. Org. Lett. 2011, 13, 6414-6417.

${ }^{7}$ For recent examples see: (a) Browne, D. L.; Baumann, M.; Harji, B. H.; Baxendale, I. R.; Ley, S. V. Org. Lett. 2011, 13, 3312-3315. (b) Fandrick, D. R. et al. Org. Process Res. Dev. 2012, DOI: 10.1021/op200180t

${ }^{8}$ Webb, D.; Jamison, T. F. Org. Lett. 2012, 14, 568-571. multistep process $^{9}$ wherein the aldehyde generated from the DIBALH reduction is not isolated or purified but undergoes a subsequent olefination transformation in a concatenated reactor (Figure 1c). ${ }^{10}$ This telescoped ${ }^{11}$ multistep synthesis ('one-flow' synthesis) of $\alpha, \beta$ unsaturated esters from esters affords the products in high yields and with excellent $E: Z$ selectivity and avoids the need to isolate or purify the aldehyde intermediates.

Our easily configured multi-reactor network (Figure 2) was assembled from standard PFA (perfluoroalkoxy alkane) tubing and T-shaped mixers (Tefzel, 0.02" inner diameter). ${ }^{12}$ The reagent streams were introduced to the system by syringe pump devices and a cooling bath was used to control the temperature $\left(-78^{\circ} \mathrm{C}\right.$ or $\left.-42^{\circ} \mathrm{C}\right)$.

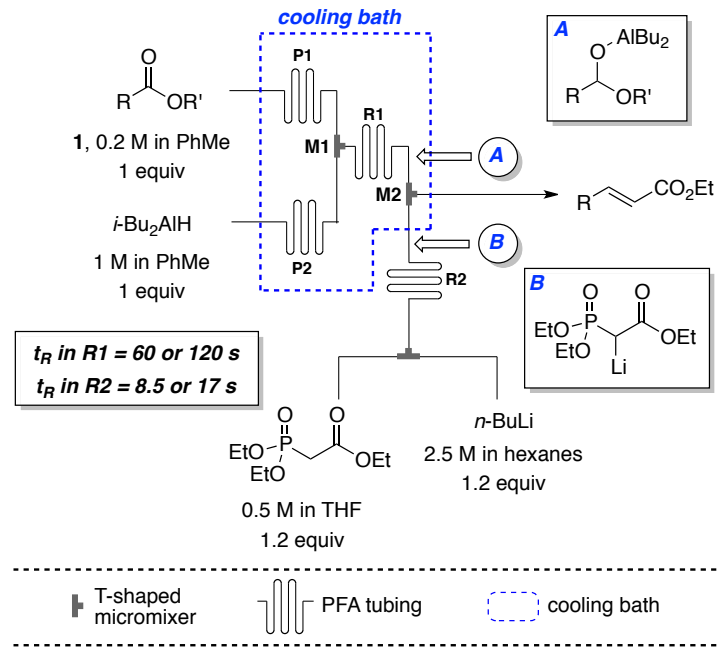

Figure 2. General experimental set-up for the continuous flow homologation. P1, P2: pre-cooling loops; M1, M2: T-shaped mixers; R1, R2, R3: reactors.

In our initial study of the DIBALH reduction of esters, we focused on developing a fast and reliable system for aldehyde synthesis. Consequently, many of our previously reported conditions employed an excess of DIBALH as this enabled extremely fast conversion to the aldehyde products. Considering the multistep homologation sequence holistically, we recognized that excess DIBALH from the reduction step would negatively impact on the Horner-Wadsworth-Emmons olefination. As a result, using the extensive amount of data we had collected previously, ${ }^{8}$ we rapidly established a general set of flow conditions that resulted in complete and selective reduction of the ester using only a

${ }^{9}$ For a review see: Webb, D.; Jamison, T. F. Chem. Sci. 2010, 1 675-680.

${ }^{10}$ For the first report of a telescoped flow process that involves the preparation and use of an aldehyde of a single substrate using a segmented flow approach see: Carter, C. F.; Lange, H.; Sakai, D.; Baxendale, I. R.; Ley, S. V. Chem. Eur. J. 2011, 17, 3398-3405.

11 Anderson, N. G. Practical Process Research \& Development; Academic Press: San Diego, 2000; Chapter 2.

${ }^{12}$ See the Supporting Information for full experimental details. 
stoichiometric quantity of DIBALH $\left(-42\right.$ or $-78{ }^{\circ} \mathrm{C}$ with an ester flow-rate of 2.5 or $5 \mathrm{~mL} \cdot \mathrm{min}^{-1}$ corresponding to a residence time $\left(t_{R}\right)$ of 60 or $120 \mathrm{~s}$, respectively). Similarly, our preliminary experiments revealed that deprotonation of the phosphonate using $n$-BuLi was fast $\left(t_{R}=8.5\right.$, or $\left.17 \mathrm{~s}\right)$ and could be conducted at room temperature. It should also be emphasized that no precipitation was observed using this reagent combination.

Table 1. Continuous telescoped homologation of esters to $\alpha, \beta$ unsaturated esters.

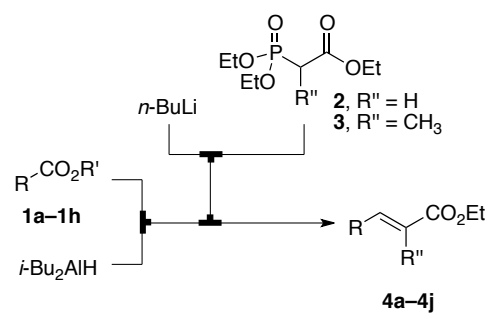

\begin{tabular}{|c|c|c|c|c|c|}
\hline entry & $\begin{array}{l}\text { starting } \\
\text { ester }\end{array}$ & $\begin{array}{c}\text { Temp. } \\
\left({ }^{\circ} \mathrm{C}\right)\end{array}$ & product & $\begin{array}{l}\text { yield } \\
(\%)^{a}\end{array}$ & $E / Z^{b}$ \\
\hline 1 & $1 \mathrm{a}$ & -42 & & 86 & $>19: 1$ \\
\hline 2 & $1 b$ & -78 & & 84 & $>19: 1$ \\
\hline 3 & 1c & -78 & & 81 & $>19: 1$ \\
\hline 4 & 1d & -42 & & 89 & $>19: 1$ \\
\hline 5 & $1 e$ & -78 & & 96 & $>19: 1$ \\
\hline 6 & 1f & -78 & & 86 & $>19: 1$ \\
\hline 7 & $1 \mathrm{~g}$ & -78 & & 89 & $>19: 1$ \\
\hline 8 & $1 \mathrm{~h}$ & -78 & $4 \mathrm{~h}$ & 99 & $>19: 1$ \\
\hline 9 & $1 \mathrm{a}$ & -78 & & 90 & $8: 1$ \\
\hline 10 & $1 \mathrm{~g}$ & -42 & & 93 & $7: 1$ \\
\hline
\end{tabular}

${ }^{a}$ All yields are isolated yields. ${ }^{b}$ Determined by ${ }^{1} \mathrm{H}$ NMR spectroscopic analysis of the crude product.

The experimental procedure is summarized as follows (Figure 2): A solution of DIBALH and a solution of ester are mixed and flowed through the first reactor (R1) at low temperature, wherein the controlled partial reduction occurs. Solutions of the phosphonate and $n$-BuLi are mixed and flowed through a second reactor (R2) wherein the phosphonate deprotonation occurs. The outlets of R1 (a solution of aluminated hemiactetal $\boldsymbol{A}^{13}$ ) and R2 (a solution of lithio-phosphonate $\boldsymbol{B}$ ) are then combined in a third mixer (which is held at low temperature). After a steady state is reached, the final eluting stream is deposited into a collection vessel and stirred until full conversion is observed, following which the product is isolated using standard methods.

Using this set-up a variety of esters were investigated as starting materials for the multistep flow process (Table 1). In all cases the desired products were obtained in high yield and with high levels of selectivity for the newly formed alkene. For example, the synthetically useful ethyl 3-hydroxy-2-methylpropanoate 1e was transformed to the homologated product $4 \mathbf{e}$ in high isolated yield with $>95 \%$ selectivity for the trans alkene (Table 1, Entry 5). The use of caprolactone $\mathbf{1 h}$ as starting material (Table 1, Entry 8) afforded the corresponding hydroxyester product $\mathbf{4 h}$ almost quantitatively. The procedure was also succesful in providing the $E$-trisubstituted olefins $4 \mathbf{i}$ and $\mathbf{4 j}$ when the phosphonopropionate $\mathbf{3}$ was employed. In all the examples the amount of unwanted overreduction to the alcohol product was negligible owing to the wellcontrolled nature of the reduction step. ${ }^{8}$

It is interesting to note that, in addition to an increase in yield, the selectivity in the olefination step was considerably higher than those reported previously using batch methods with similar reagents. ${ }^{14}$ Also worthy of note is the use of volatile and sensitive aldehydes, which are experimentally challenging to handle when isolated prior to the olefination step. For example, the aldehyde obtained from the silyl ether of ethyl lactate (Table 1, Entry 4) is volatile and prone to racemization when purified. ${ }^{15}$ In our system this ester underwent partial reduction and subsequent olefination without incident to give the desired product $\mathbf{4 d}$ in high yield and selectivity.

In conclusion, an efficient protocol has been developed for the highly selective and high-yielding continuous synthesis of $\alpha, \beta$-unsaturated esters from esters. The mediation of 2 organometallic reactions in a telescoped flow format should facilitate the rapid scale up ${ }^{7}$ of this useful series of transformations. The aldehyde intermediates do not have to be isolated or purified which greatly minimizes the amount of waste generated for the sequence. Our future research endeavours are focused on the evaluation and development of other telescoped transformations.

Acknowledgment The authors would like to thank Novartis for its generous financial support of the Novartis-MIT Center for Continuous Manufacturing (CCM). Dr. Melissa Blackman is thanked for some

${ }^{13}$ (a) Polt, R.; Peterson, M. A.; DeYoung, L. J. Org. Chem. 1992, 57, 5469-5480. (b) Kiyooka, S.; Shirouchi, M.; Kaneko, Y. Tetrahedron Lett. 1993, 34, 1491-1494.

${ }^{14}$ For example see reference 6(a) and: Claridge, T. D. W.; Davies, S. G.; Lee, J. A.; Nicholson, R. L.; Roberts, P. M.; Russell, A. J.; Smith, A. D.; Toms, S. M. Org. Lett. 2008, 10, 5437-5440.

${ }_{15}$ Marshall, J. A.; Yanik, M. M.; Adams, N. A.; Ellis, K. C.; Chobanian, H. R. Org. Synth. Coll. Vol. 11, 2009, 615-625. 
preliminary experiments and Eric Standley for performing HRMS analyses.

Supporting Information Available Experimental procedures and analytical data. This material is available free of charge via the Internet at http://pubs.acs.org. 